American Journal of Applied Sciences 8 (12): 1398-1403, 2011

ISSN 1546-9239

(C) 2011 Science Publications

\title{
Applying Fuzzy Analytic Hierarchy Process and Grey Relation Analysis to Evaluate the Supply Chain Performance of the Wafer Testing House
}

\author{
${ }^{1}$ Yun-Chin Chen, ${ }^{2}$ Jun-Yuan Kuo and ${ }^{3}$ Bang-Ting Luo \\ ${ }^{1}$ Department of Business Administration, De Lin Institute of Technology, \\ No.1, Ln. 380, Qingyun Rd., Tucheng Dist, New Taipei City 236, (ROC), Taiwan \\ ${ }^{2}$ Department of International Business, Kainan University, \\ ${ }^{3}$ Department of International Business, Kainan University, \\ No.1 Kainan Road, Luzhu Shiang, Taoyuan 338, (R.O.C), Taiwan
}

\begin{abstract}
Problem statement: In the information age, the process of E-Commerce (EC) operates quickly and the present enterprises of Taiwan have to face the Free Cross-Strait Market (FCSM) with Mainland China, which will definitely change the model as well as the performance of the supply chain. Hence, this study focuses on the issue of supply chain performance evaluation of the wafer testing house in Taiwan. Approach: This investigation applied the Fuzzy Analytic Hierarchy Process (FAHP) to derive the weights of influential indicators for evaluating the supply chain performance of the wafer testing house and the Grey Relation Analysis (GRA) was used to evaluate the performance between the FCSM and EC aspects. Results: The analyzed results had identified the indicator weight of the supply chain performance evaluation in the wafer testing house and the indicator performances between different aspects were compared. The research results indicated that the FCSM aspect had better performance than EC aspect of the supply chain evaluation in the wafer testing house. Conclusion/Recommendations: Based on the analyzed results, the managers can find out the problems and improve the supply chain performance of the wafer testing house. This study not only can be a good basis for improvements of the case company, but also can be the reference for evaluating the supply chain performance of the wafer testing house.
\end{abstract}

Key words: Fuzzy analytic hierarchy process, grey relation analysis, supply chain management, wafer testing house, performance evaluation, fuzzy theory, E-Commerce (EC)

\section{INTRODUCTION}

In the 21 st century, the enterprises have to face the global competitions. The performance of the global Supply Chain Management (SCM) has great influence on enterprises and the E-Commerce (EC) has played an important role of the global SCM. In addition, due to the Free Cross-Strait Market (FCSM) of the Mainland China and Taiwan, the supply chain operation of the enterprises in Taiwan will face great challenge in the future. Therefore, it is an urgent issue for enterprises to evaluate the performance of supply chain.

This study has applied the Fuzzy Analytic Hierarchy Process (FAHP) and Grey Relation Analysis (GRA) to evaluate the supply chain performance of the wafer testing house. The data and information are collect from a wafer testing house in Taiwan. The results can be used as a basis for improving the supply chain performance of the wafer testing houses, providing the reference information of the supply chain performance evaluation in the semiconductor industry.

\section{MATERIALS AND METHODS}

The fuzzy theory and concept was developed by Zadeh (1965) which is a famous theory and widely applied in various fields. The methodology of Analytic Hierarchy Process (AHP) was proposed by Saaty (1980) which is a good method to analyze problems. Many researchers have applied the fuzzy theory and AHP to solve the focused problems (Sujatha and Santhanam, 2010). Numerous researchers have focus on the issue of website, database, learning theory and EC (Rjoub et al., 2009; Sundaram et al., 
Am. J. Applied Sci., 8 (12): 1398-1403, 2011

2010; Erikson and Carifio, 2009; Igau et al., 2011; Nardal and Sahin, 2011)

In the research field of supply chain performance management, many researchers have involved in the relevant subjects. Lee et al. (2001) investigated supply chain management from the perspective of manufacturer management. Angeles (2005) focused on the research of supply chain management from the IT perspective. Easton et al. (2002) investigated the procurement performance evaluation of the supply chain. Lai et al. (2002) focused on the supply chain performance evaluation and measurement of the logistics. Radhakrishnan et al. (2009) investigated the optimizing inventory for efficient supply chain management. Manzouri et al. (2011) focused on the research of order management in supply chain.

According to the above research materials, we can understand that many researchers had focus on the SCM of various industries, but there is few literatures focus on the supply chain performance evaluation of wafer testing house. Therefore, this investigation aims to use FAHP and GRA to evaluate the supply chain performance of wafer testing house, which serve as a basis of reference and decision-making for the wafer testing house.

Fuzzy Analytic Hierarchy Process (FAHP): Laarhoven and Pedrycz (1983) developed the FAHP method based on the AHP method proposed by Saaty (1980) and the FAHP has been widely adopted in many different issues, which can define and analyze the problems and elements efficiently. Therefore, this study has applied the FAHP method to find out the indicator weights of the supply chain performance evaluation of the wafer testing factory.

The calculation of FAHP of this study is based primarily on the concept and methods developed by Buckley (1985) and the trapezoidal fuzzy numbers (TrFN) of Buckley (1985) are substituted by triangular fuzzy numbers. The calculation steps of FAHP are outlined as follows (Zadeh, 1965; Saaty, 1980; Laarhoven and Pedrycz, 1983; Buckley, 1985; Zhao and Govind, 1991; Tzeng and Teng, 1993):

- Build the hierarchical structure for the goal of investigation and derive a fuzzy pairwise comparison matrix

- Calculate the fuzzy number and fuzzy weights of the fuzzy positive reciprocal matrix

- Defuzzification: Conversion of fuzziness into exact values is defined as defuzzification. This research applied the best nonfuzzy performance value (Zadeh, 1965; Zhao and Govind, 1991; Tzeng and
Teng, 1993; Opricovic and Tzeng, 2003) for defuzzification

- Normalization and the hierarchy coordination

Grey relation analysis: The GRA method was proposed by Ju-Long (1982), which can use to sort and analyze the relationship between various factors. The Chen and Tzeng (2004) has develop a method which has combined the grey relationship and technique for order preference by similarity to ideal solution (TOPSIS) concepts to evaluate various criteria for choosing the host country and the results indicated that the method of combining grey relation and TOPSIS is an effective appraisal (Chen and Tzeng, 2004). Therefore, this study has applied the combination method of grey relationship and TOPSIS concepts which was proposed by Chen and Tzeng (2004) to evaluate the supply chain performance of wafer testing house. The main steps are illustrated as follow (Chen and Tzeng, 2004):

- Build the evaluation matrix and obtain the positive/negative perfect value and the $P\left(x^{*}(j),\left(x_{i}(j)\right)\right)$ represents the positive perfect value and the $P\left(x^{-}(j), x_{i}(j)\right)$ indicates the negative perfect value (Chen and Tzeng, 2004)

- Identify the parameters of GRA and comparative distance $\left(\mathrm{D}_{\mathrm{i}}\right)$, the $\mathrm{P}\left(\mathrm{x}^{*}, \mathrm{x}_{\mathrm{i}}\right)$ and the $\mathrm{P}\left(\mathrm{x}^{-}, \mathrm{x}_{\mathrm{i}}\right)$ represents the Grey Relation Grade (GRG) of positive and negative perfect value, respectively (Chen and Tzeng, 2004)

- The higher value of $D_{i}$ shows the superior evaluation of the option (Chen and Tzeng, 2004). The more the $\mathrm{P}\left(\mathrm{x}^{*}, \mathrm{x}_{\mathrm{i}}\right)$ approaching to 1 , the better performance it exhibits; the more the $\mathrm{P}\left(\mathrm{x}^{-}, \mathrm{x}_{\mathrm{i}}\right)$ approaching to 1 , the worse performance it indicates (Chen and Tzeng, 2004)

- Analyze and derive the evaluation results (Chen and Tzeng, 2004)

\section{RESULTS}

In order to understand the supply chain evaluation of the wafer testing house, this study has collected the data and information from a wafer testing house in Taiwan and the FAHP is adopted to find out the weights of indicators to evaluate the supply chain performance in the wafer testing factory. This study applied the decision making structure of the supply chain proposed by Chopra and Meindl (2003) as the main focus and basis and the questionnaire of this study is designed based on Chopra and Meindl (2003) research. The questionnaires are distributed to 38 managers and team 
leaders of the wafer testing factory in Taiwan.

After collected and analyzed the questionnaires, the weights of supply chain performance indicators of the wafer testing factory were identified, as shown in Table 1.

Based on the analyzed results in Table 1, it is shown that the logistic factor is recognized as the most important factor of the supply chain performance in the case company and the facilities of the logistic factor related to productivity and utilization rate may greatly affect the supply chain performance of the wafer testing house.

According to the global environment and the high speed internet technologies, the FCSM and the EC have become two of important aspects for the supply chain performance evaluation in Taiwan. Therefore, this study has applied the combination method of grey relationship and TOPSIS concepts that was developed by Chen and Tzeng (2004) to evaluate the supply chain performance and analyze the aspects of FCSM and EC of the wafer testing house, the indicator weights which derived from the FAHP were used in the combination method of the grey relationship and TOPSIS concepts (Chen and Tzeng, 2004) and the scale of 1-5 has adopted to represent the different level of performance from very bad to very good (Chen and Tzeng, 2004). The corresponding values of the two aspects are shown in Table 2 and the Table 3 contains the grey relational parameters of each criterion and the $\mathrm{D}_{\mathrm{i}}$ of the FCSM and EC aspect.

Table 1: The indicators weights of the supply chain performance in the wafer testing factory

\begin{tabular}{|c|c|c|c|c|}
\hline $\begin{array}{l}\text { Factor } \\
\text { (factor weights) }\end{array}$ & $\begin{array}{l}\text { Criteria/ } \\
\text { (criteria weights) }\end{array}$ & $\begin{array}{l}\text { Indicator } \\
\text { (indicator weights) }\end{array}$ & Overall weights & Overall ranking \\
\hline \multirow{12}{*}{$\begin{array}{l}\text { Logistic factor } \\
(0.6796)\end{array}$} & \multirow[t]{5}{*}{ Facilities $(0.5708)$} & Productivity $(0.3346)$ & 0.1298 & 1 \\
\hline & & Utilization rate $(0.3098)$ & 0.1202 & 2 \\
\hline & & Theoretical production cycle $(0.1113)$ & 0.0432 & 10 \\
\hline & & Actual average cycle $(0.1261)$ & 0.0489 & 7 \\
\hline & & Production time/lead time/halt time/idle time $(0.1182)$ & 0.0459 & 8 \\
\hline & \multirow[t]{4}{*}{ Inventory $(0.2542)$} & Average inventory $(0.4124)$ & 0.0712 & 3 \\
\hline & & $\begin{array}{l}\text { Products stored for more than specified number of days } \\
(0.2603)\end{array}$ & 0.045 & 9 \\
\hline & & Supply ratio $(0.2068)$ & 0.0357 & 14 \\
\hline & & Spare parts in stock $(0.1205)$ & 0.0208 & 17 \\
\hline & \multirow[t]{3}{*}{ Transportation $(0.1750)$} & Average incoming transportation cost $(0.5047)$ & 0.0600 & 5 \\
\hline & & Average outgoing transportation cost $(0.3343)$ & 0.0398 & 12 \\
\hline & & Ratio of different transportation means $(0.1610)$ & 0.0192 & 18 \\
\hline Cross-functional factor & Information $(0.5465)$ & Estimated period $(0.3460)$ & 0.0605 & 4 \\
\hline \multirow[t]{11}{*}{$(0.3204)$} & & Renewal frequency $(0.3210)$ & 0.0562 & 6 \\
\hline & & Estimated errors $(0.2139)$ & 0.0375 & 13 \\
\hline & & Seasonal factors $(0.1191)$ & 0.0209 & 16 \\
\hline & \multirow[t]{4}{*}{ Procurement $(0.2701)$} & Average purchasing price $(0.4702)$ & 0.0407 & 11 \\
\hline & & Average purchased quantity $(0.1701)$ & 0.0147 & 21 \\
\hline & & Ratio of punctual delivery (0.1724) & 0.0149 & 20 \\
\hline & & Supply quality $(0.1873)$ & 0.0162 & 19 \\
\hline & \multirow[t]{4}{*}{ Pricing $(0.1834)$} & Net profit $(0.5033)$ & 0.0296 & 15 \\
\hline & & Number of days of debt payment delay $(0.2277)$ & 0.0133 & 22 \\
\hline & & Average selling price $(0.1533)$ & 0.009 & 23 \\
\hline & & Average order quantity $(0.1157)$ & 0.0068 & 24 \\
\hline
\end{tabular}

Table 2: The average scale value of each criterion

\begin{tabular}{lllll}
\hline Criteria & The good value $x^{*}$ & The bad value $x^{*}$ & FCSM & EC \\
\hline Productivity & 5 & 1 & 3.5313 & 3.3438 \\
Utilization rate & 5 & 1 & 3.5313 & 3.4375 \\
Theoretical production cycle & 5 & 1 & 3.5938 & 3.5000 \\
Actual average cycle & 5 & 1 & 3.6250 & 3.4375 \\
Production time /lead time /machine halt time/idle time & 5 & 1 & 2.9375 & 3.1875 \\
Average inventory & 5 & 1 & 3.3750 & 3.6250 \\
Products stored for more than specified number of days & 5 & 1 & 3.3438 & 3.3438 \\
Supply ratio & 5 & 1 & 3.2500 & 3.3125 \\
Spare parts in stock & 5 & 1 & 3.6250 & 3.2813 \\
Average incoming transportation cost & 5 & 1 & 3.9063 & 3.0313 \\
Average outgoing transportation cost & 5 & 1 & 3.8125 & 3.0313 \\
Ratio of different transportation means & 5 & 1 & 3.7813 & 3.2500 \\
Estimated period & 5 & 1 & 3.2813 & 3.2813 \\
Renewal frequency & 5 & 1 & 3.0938 & 3.5000 \\
\hline
\end{tabular}


Am. J. Applied Sci., 8 (12): 1398-1403, 2011

Table 2: Continue

\begin{tabular}{lllll}
\hline Estimated errors & 5 & 1 & 2.9063 & 3.6875 \\
Seasonal factors & 5 & 1 & 3.0938 & 3.9688 \\
Average purchasing price & 5 & 1 & 3.5313 & 3.0000 \\
Average purchased quantity & 5 & 1 & 3.6563 & 3.3125 \\
Ratio of punctual delivery & 5 & 1 & 3.7188 & 3.7500 \\
Supply quality & 5 & 1 & 3.2500 & 3.2188 \\
Net profit & 5 & 1 & 3.5625 & 3.4375 \\
Number of days of debt payment delay & 5 & 1 & 3.0938 & 3.3125 \\
Average selling price & 5 & 1 & 3.5000 & 3.3750 \\
Average order quantity & 5 & 3.4375 & 3.5000 \\
\hline
\end{tabular}

Table 3: The GRA parameters of each criterion

\begin{tabular}{|c|c|c|c|c|}
\hline \multirow[b]{2}{*}{ Criteria } & \multicolumn{2}{|l|}{ FCSM } & \multicolumn{2}{|l|}{$\mathrm{EC}$} \\
\hline & $P\left(x^{*}(j), x_{i}(j)\right)$ & $P\left(x^{-}(j), x_{i}(j)\right)$ & $P\left(x^{*}(j), x_{i}(j)\right)$ & $P\left(x^{-}(j), x_{i}(j)\right)$ \\
\hline Productivity & 0.8510 & 0.8431 & 0.8480 & 0.8992 \\
\hline Utilization rate & 0.8510 & 0.8431 & 0.8788 & 0.8770 \\
\hline Theoretical production cycle & 0.8726 & 0.8301 & 0.9006 & 0.8629 \\
\hline Actual average cycle & 0.8839 & 0.8238 & 0.8788 & 0.8770 \\
\hline Production time/lead time/machine halt time/idle time & 0.6885 & 0.9908 & 0.8011 & 0.9386 \\
\hline Average inventory & 0.8012 & 0.8776 & 0.9477 & 0.8359 \\
\hline Products stored for more than specified number of days & 0.7919 & 0.8848 & 0.8480 & 0.8992 \\
\hline Supply ratio & 0.7654 & 0.9072 & 0.8382 & 0.9068 \\
\hline Spare parts in stock & 0.8839 & 0.8238 & 0.8286 & 0.9145 \\
\hline Average incoming transportation cost & 1.0000 & 0.7706 & 0.7592 & 0.9817 \\
\hline Average outgoing transportation cost & 0.9581 & 0.7875 & 0.7592 & 0.9817 \\
\hline Ratio of different transportation means & 0.9449 & 0.7934 & 0.8192 & 0.9224 \\
\hline Estimated period & 0.7740 & 0.8996 & 0.8286 & 0.9145 \\
\hline Renewal frequency & 0.7249 & 0.9471 & 0.9006 & 0.8629 \\
\hline Estimated errors & 0.6816 & 1.0000 & 0.9732 & 0.8231 \\
\hline Seasonal factors & 0.7249 & 0.9471 & 0.7436 & 1.0000 \\
\hline Average purchasing price & 0.8510 & 0.8431 & 0.7513 & 0.9907 \\
\hline Average purchased quantity & 0.8954 & 0.8175 & 0.8382 & 0.9068 \\
\hline Ratio of punctual delivery & 0.9195 & 0.8052 & 1.0000 & 0.8106 \\
\hline Supply quality & 0.7654 & 0.9072 & 0.8101 & 0.9304 \\
\hline Net Profit & 0.8617 & 0.8366 & 0.8788 & 0.8770 \\
\hline Number of days of debt payment delay & 0.7249 & 0.9471 & 0.8382 & 0.9068 \\
\hline Average selling price & 0.8405 & 0.8498 & 0.8580 & 0.8917 \\
\hline Average order quantity & 0.8204 & 0.8635 & 0.9006 & 0.8629 \\
\hline Grey relation evaluation & $\mathrm{P}\left(\mathrm{x}^{*}, \mathrm{x}_{\mathrm{i}}\right)=0.8304$ & $\mathrm{P}\left(\mathrm{x}^{-}, \mathrm{x}_{\mathrm{i}}\right)=0.8659$ & $\mathrm{P}\left(\mathrm{x}^{*}, \mathrm{x}_{\mathrm{i}}\right)=0.8533$ & $\mathrm{P}\left(\mathrm{x}^{-}, \mathrm{x}_{\mathrm{i}}\right)=0.9007$ \\
\hline $\mathrm{D}_{\mathrm{i}}$ & 0.9590 & & 0.9474 & \\
\hline
\end{tabular}

\section{DISCUSSION}

Based on the above analysis results and outcome, we can understand that the top three supply chain performance indicators that the company highly regards are productivity, utilization rate and average inventory and the least important indicator is the average order quantity. Maybe it is because that the facility purchasing and operating cost in the wafer testing factory are very high and the managers have to pay attention to the productivity and utilization rate of the machines for the operational efficiency. The manager should also concern about the average inventory to reduce the unnecessary cost and enhance the inventory control of the wafer testing house.

According to Table 3 , the performance between different aspects of supply chain were identified and compared. It can be known that the indicator of average incoming transportation cost has the best performance in the FCSM aspect and the improvements of the estimated errors and the production time of the FCSM are required. In the $\mathrm{EC}$ aspect, the ratio of punctual delivery has the best performance and performance of the seasonal factors and average purchasing price will have to be improved. The managers may concern about the purchase order variation from the seasonal factor and pay attention to the variation of average purchasing price in the wafer testing house.

As shown in Table 3, the $\mathrm{D}_{i}$ of FCSM is 0.9590, which is higher than 0.9474 of EC. Therefore, we can understand that the aspect of FCSM has better performance than EC of the supply chain evaluation in this wafer testing house. Therefore, the managers should pay attention to the EC aspect and improve the EC performance according to the analysis results of indicators. 


\section{CONCLUSION}

This study has applied the FAHP and GRA method to evaluate the supply chain performance of the wafer testing house and the verification has done in a case company in Taiwan. The analysis results indicated that the productivity, utilization rate and average inventory are more important than other supply chain performance indicators in the wafer testing house. This research also analyzed and compared the performance of the FCSM and EC aspect in the wafer testing house, the result shows that the FCSM has better performance than EC in this case company and the indicators which need improvement of the FCSM and EC aspect were identified. The managers can find out the problems and improve the operation process based on the analyzed results.

This research not only can be a good foundation for improving the supply chain performance of the case company, but also can be the reference to appraise the supply chain performance in the wafer testing house.

\section{REFERENCES}

Angeles, R., 2005. RFID technologies: Supply-chain applications and implementation issues. Inform. Syst. Manage., 22: 51-65. DOI: 10.1201/1078/44912.22.1.20051201/85739.7

Buckley, J.J., 1985. Fuzzy hierarchical analysis. Fuzzy Sets Syst., 17: 233-247. DOI: 10.1016/01650114(85)90090-9

Chen, M.F. and G.H. Tzeng, 2004. Combining grey relation and TOPSIS concepts for selecting an expatriate host country. Math. Comput. Model, 40:1473-1490. DOI: 10.1016/j.mcm.2005.01.006

Chopra, S. and P. Meindl, 2003. Supply Chain Management: Strategy, Planning and Operations. 2nd Edn., Prentice Hall, Taiwan ISBN-10: 013101028X, pp: 592.

Easton, L., D.J. Murphy and J.N. Pearson, 2002. Purchasing performance evaluation: With data envelopment analysis. Eur. J. Purch Supply Manag., 8:123-134. DOI: 10.1016/S09697012(02)00002-3

Erikson, L. and J. Carifio, 2009. Implementing the current science and citizenship mandates: A learning theory analysis and set of recommendations. J. Soc. Sci., 5: 193-205. DOI: 10.3844/jssp.2009.193.205

Igau, O.A., A.W.M. Kassim., S. Tahajuddin., N.O. Ndubisi and M.G. Hassan, 2011. Non-business ecommerce in Malaysia: An investigation of key adoption. Am. J. Eng. Applied Sci., 3: 177-185. DOI: 10.3844/ajebasp.2011.177.185
Ju-Long, D., 1982. Control problems of grey systems. Syst. Control Lett., 1: 288-294. DOI: 10.1016/S0167-6911(82)80025-X

Laarhoven, P.J.M. and W. Pedrycz, 1983. A fuzzy extension of Saaty's priority theory. Fuzzy Sets Syst., 11: 199-227. DOI: 10.1016/S01650114(83)80082-7

Lai, K.H., E.W.T. Ngai and T.C.E. Cheng, 2002. Measures for evaluating supply chain performance in transport logistics. Transp. Res. Pt. e-Logist. Transp. Rev., 38: 439-456. DOI: 10.1016/S13665545(02)00019-4

Lee, E.K., S. Ha and S.K. Kim, 2001. Supplier selection and management system considering relationships in supply chain management. IEEE Trans. Eng. Manage., 48: 307-318. DOI: 10.1109/17.946529

Manzouri, M., M.N.A. Rahman and H. Arshad, 2011. Order management in supply chain: A case study in automotive companies. Am. J. Eng. Applied Sci., $\quad 4: \quad 372-379 . \quad$ DOI: 10.3844/ajeassp.2011.372.379

Nardal, S. and A. Sahin, 2011. Ethical issues in ecommerce on the basis of online retailing. J. Soc. Sci., 7: 190-198. DOI: 10.3844/jssp.2011.190.198.

Opricovic, S. and G.H. Tzeng, 2003. Defuzzification within a multicriteria decision model. Int. J. Uncertainty Fuzziness Knowl. Based Syst., 11: 635-652. DOI: $10.1142 / \mathrm{S} 0218488503002387$

Radhakrishnan P., W. M. Prasad and M. R. Gopalan, 2009. Optimizing inventory using genetic algorithm for efficient supply chain management. J. Comput. Sci., 5: 233-241. DOI: 10.3844/jcssp.2009.233.241

Rjoub,A., Y. Eyadat, A. Ghazawi, B. Tall, N. Sharou and L. Mardeeni, 2009. A multi-form multiple choice editor exam tool based on HTML website and artificial intelligence techniques. J. Comput. Sci., 5: 405-412. DOI: 10.3844/jcssp.2009.405.412

Saaty, T.L., 1980. The Analytic Hierarchy Process: Planning, Priority Setting, Resource Allocation. 1st Edn., McGraw-Hill, New York, ISBN: 0070543712, pp: 287.

Sujatha, B. and T. Santhanam, 2010. Classical flexible lip model based relative weight finder for better lip reading utilizing multi aspect lip geometry. J. Comput. Sci., 6: 1065-1069. DOI: 10.3844/jcssp.2010.1065.1069

Sundaram, K.M., T. Santhanam, M. Saroja and C.P. Sumathi, 2010. A performance analysis of modified mid-square and mid-product techniques to minimize the redundancy for retrieval of database records. J. Comput. Sci., 6: 386-391. DOI: 10.3844/jcssp.2010.386.391 
Tzeng, G.H. and J.Y. Teng, 1993. Transportation investment project selection with fuzzy multiobjective. Trans. Plan. Technol., 17: 91-112. DOI: $10.1080 / 03081069308717504$
Zadeh, L.A., 1965. Fuzzy sets. Inform. Cont., 8: 338353. DOI: $10.1016 / \mathrm{S} 0019-9958(65) 90241-X$

Zhao, R. and R. Govind, 1991. Algebraic characteristics of extended fuzzy numbers. Inf. Sci., 54:103-130. DOI: 10.1016/0020-0255(91)90047-X 